ORIGINAL ARTICLE

\title{
Cancer risk in offspring of male pesticide applicators in agriculture in Sweden
}

\author{
Y Rodvall, J Dich, K Wiklund
}

Occup Environ Med 2003;60:798-801

See end of article for authors' affiliations

....................

Correspondence to: Dr Y Rodvall, Department of Occupational and Environmental Health Norrbacka level 3, SE-171 76 Stockholm, Sweden: ylva.rodvall@smd.sll.se

Accepted

17 December 2002

\begin{abstract}
Aims: To explore cancer risk from date of birth until 1994 in children, born 1958 or later, of Swedish male pesticide applicators.

Methods: Records of male pesticide applicators licensed 1965-76 were linked to the Multigeneration Register. The records of their offspring were then linked to the Swedish Cancer Registry and the Cause of Death Register.

Results: In total 51 cases of cancer were observed, which is significantly lower than the expected 73.0 (standardised incidence ratio (SIR) $0.70,95 \% \mathrm{Cl} 0.52$ to 0.92 ). Tumours of the nervous system was most common, amounting to 20 cases, $39 \%$ of all cancer cases (SIR 1.01, $95 \% \mathrm{Cl} 0.62$ to 1.56 ). A statistically significant reduced risk for leukaemia was found (SIR $0.43,95 \% \mathrm{CI} 0.19$ to 0.86 ). For non-Hodgkin's lymphoma, three cases were observed and 4.8 expected (SIR $0.63,95 \% \mathrm{Cl} 0.13$ to 1.83 ). For Hodgkin's disease, five cases were observed versus 3.7 expected (SIR 1.36, 95\% $\mathrm{Cl} 0.44$ to 3.17). Two cases of testicular cancer were observed and 1.7 expected (SIR $1.19,95 \% \mathrm{Cl} 0.13$ to 4.28 ).

Conclusions: None of the a priori hypotheses of increased risk of tumours of the nervous system, kidney cancer, leukaemia, lymphoma, soft tissue sarcoma, and testicular cancer in children of male pesticide applicators could be confirmed.
\end{abstract}

n Sweden around 350 of the annual 45000 new cases of primary cancer were diagnosed in persons under 20 years of age in 2000. Tumours in the nervous system (31\%) and leukaemia $(22 \%)$ are the most common diagnoses in this age group. ${ }^{1}$

Current understanding of the aetiology of childhood cancer is limited and little is known about the role of environmental carcinogens. ${ }^{2} 3$ Ionising radiation, chemotherapeutic agents, and diethylstilboestrol are well established risk factors for childhood cancer. ${ }^{4}$ In the search for environmental factors that could cause cancer in children, attention has been focused on the role of parental exposures, particularly on occupational factors, but none has so far been established as a causal factor. Epidemiological studies have suggested increased risks of childhood cancers in children of workers, mainly fathers, exposed to magnetic fields, paints, solvents, petroleum products, metals, radiation, and agricultural chemicals. ${ }^{4-8}$ None of these studies have provided data to indicate how the occupational exposure might affect their offspring.

Parental exposures to pesticides have been suspected risk factors for kidney cancer, acute leukaemia, soft tissue sarcoma, non-Hodgkin's lymphoma, brain cancer, testicular cancer, colorectal cancer, and Ewings bone sarcoma. ${ }^{8-15}$ Residence on a farm, a proxy for pesticide exposure, has been associated with increased risk of a number of childhood cancers. ${ }^{9}{ }^{14} 16$ An increased risk of leukaemia was found for children whose parents used pesticides at home. ${ }^{17}{ }^{18}$ Pesticide use in the home has also been linked with childhood soft tissue sarcoma, brain tumours, and lymphoma. ${ }^{19-21}$ Indoor use of some insecticides and pesticide use in the garden and on interior plants was associated with increased risks of childhood leukaemia. ${ }^{18}$ The possibility of phenoxy acid herbicides being a cause of soft tissue sarcomas and lymphomas in adults is of interest, as these malignancies are relatively common in childhood and adolescence. In utero and childhood exposures to compounds with oestrogenic activity have been correlated with changes in male reproductive health and fertility and might be related to the increased risk of testicular cancer. ${ }^{22}$ So far, however, the results are not consistent and an aetiological relation between pesticide exposure and specific childhood cancer is far from proven. One should bear in mind that childhood cancers are not aetiologically homogeneous diseases, and from a biological perspective perhaps specific histology types of tumours should be studied.

Pesticides may enter the body by dermal absorption, inhalation, or oral absorption. ${ }^{10}{ }^{23}$ Potential mechanisms by which pesticides may lead to cancer in humans remain speculative. Animal studies have shown that pesticides exert their carcinogenic effect through a variety of mechanisms: genotoxicity, tumour promotion, hormonal action, immunotoxicity, and peroxisome proliferation. ${ }^{1024}$ Immunological mechanisms triggered by pesticides are suspected to be important for the development of leukaemia in adults.

The environment on the farm is supposed to be contaminated, and young children who are likely to spend a large proportion of their time on the floor or ground, and who frequently put objects in their mouths could be exposed. Some children may accompany their parents to the fields. Children have a larger surface to volume ratio than adults, resulting in a larger proportion of skin surface across which absorption can occur. ${ }^{25}$

Farmers have a lower overall cancer incidence than the general population in Sweden. ${ }^{26}$ Most of the specific cancer diagnoses showed decreased risks, especially those associated with tobacco smoking. Increased risks were found for lip cancer, skin carcinoma, and malignant melanoma in the head-neck region, mainly due to sunlight exposure. The risks of multiple myeloma and stomach cancer were also increased. Swedish pesticide applicators have the same cancer pattern as farmers, except for prostate and testicular cancer, which is in excess among applicators. ${ }^{2428}$ A large cohort study concerning cancer in offspring of parents engaged in agricultural activities conducted in Norway showed that use of pesticides was associated with cancer at 


\section{Main messages}

- None of the findings in published studies of increased risk of tumours of the nervous system, kidney cancer, leukaemia, lymphoma, soft tissue sarcoma, and testicular cancer could be confirmed.

- Since this study is small we plan to extend the cohort by adding pesticide applicators licensed in the year 1977 and onwards by using information from The Swedish Board of Agriculture to further investigate a possible relation between paternal exposure to pesticide and cancer risk in their offspring.

an early age. ${ }^{9}$ A significantly increased risk of testicular cancer and non-significant increased risks of tumours of endocrine glands, bone tumours, and Hodgkin's disease were found. A dose-response relation was found between incidence of tumours of the nervous system and use of pesticides. In other studies risk estimates for children of farmers or agricultural workers have not deviated much from the null. ${ }^{29-32}$

In Sweden, applicators are the most appropriate occupational group for studying effects of pesticides on cancer, but also for investigating carcinogenic effects in their offspring. The aim of this retrospective cohort study was to explore cancer risk among children of male pesticide applicators in comparison with children in the general population.

\section{METHODS}

The present study included offspring to licensed pesticide applicators who were followed up for incident cancer in the Cancer Registry. Information was linked from several registers: pesticide applicators licensed 1965-76, Multigeneration Register, Cancer Registry, and Cause of Death Register. The linkage was possible since each register included the personal identification number. This number is unique to all citizens in Sweden and consists of 10 digits: two each for year, month, and day of birth; a three digit serial number; and a check digit.

The cohort of offspring of male pesticide applicators was created by linking the computerised cohort of 20245 pesticide applicators licensed 1965-76 with the Multigeneration Register. In total 27329 offspring born between 1958 and 1994 were identified.

Date of death was derived from the Cause of Death Register when an offspring was deceased. The offspring cohort was thereafter followed up in the Cancer Registry from date of birth until death or 31 December 1994. Notification to the Cancer Registry of all malignant and some benign tumours has been compulsory for all physicians and pathologists since the establishment in 1958. Each case is thus in general reported from two different sources.

The expected number of incident cases in the offspring cohort was calculated on the basis of annual cancer incidence in fiveyear age groups for the whole country. The standardised incidence ratio (SIR) was computed as the ratio between the observed and expected number of cases. The observed number of cases was assumed to be Poisson distributed, and a 95\% confidence interval for SIR was derived by means of Poisson distribution tables. ${ }^{33}$

A priori hypotheses based on previous studies were that this cohort had increased risk of tumours of the nervous system, kidney cancer, leukaemia, lymphoma, soft tissue sarcoma, and testicular cancer.

Since the number of statistical significant findings is directly related to the number of significance tests performed, the possibility of some findings being due to chance is likely to be enhanced when testing several hypotheses. However, no correction for multiplicity has been performed in the calculations of confidence intervals.

\section{RESULTS}

Among the offspring, 51.5\% were males and $48.5 \%$ were females. Table 1 presents the distributions of year of birth among the children and father's year of license for pesticide application. The mean age at diagnosis was 9.3 (SD 6.4). Table 2 shows the year of diagnosis distribution.

Table 3 presents observed and expected numbers of cases and SIR for selected cancer sites. In total 51 cases of cancer were observed in the follow up of 472461 person-years, significantly lower than the expected 73.0 (SIR 0.70, 95\% CI 0.52 to 0.92 ).

\section{Tumours of the nervous system}

This site was the most common, amounting to $39 \%$ of all cases of cancer in the cohort. The observed number of tumours was close to the number expected, 20 cases; SIR was 1.01 (95\% CI 0.62 to 1.56 ). The majority of the tumours were localised in the brain and the meninges.

\section{Leukaemia}

A statistically significant reduced risk for leukaemia was found (SIR $0.43,95 \%$ CI 0.19 to 0.86 ). Seven of the eight observed cases were acute lymphatic leukaemia; the other was a blast and stem cell leukaemia.

\section{Lymphoma}

With regard to non-Hodgkin's lymphoma, three cases were observed as against 4.8 expected (SIR $0.63,95 \%$ CI 0.13 to 1.83). For Hodgkin's disease, there were five cases observed versus 3.7 expected (SIR 1.36, 95\% CI 0.44 to 3.17 ).

\section{Testicular cancer}

With regard to testicular cancer, two cases were observed and 1.7 expected (SIR $1.19,95 \%$ CI 0.13 to 4.28 ).

Table 1 Distribution of gender, year of birth, and father's year of license for pesticide application among offspring to pesticide applicators born 1958-94

\begin{tabular}{lr}
\hline & $\%$ \\
\hline Gender & \\
Males & 51.5 \\
Females & 48.5 \\
Year of birth & 7.0 \\
$1958-59$ & 18.0 \\
$1960-64$ & 18.9 \\
$1965-69$ & 19.1 \\
$1970-74$ & 15.9 \\
$1975-79$ & 11.4 \\
$1980-84$ & 7.1 \\
$1985-89$ & 2.7 \\
$1990-94$ & 26.3 \\
Year of license & 10.0 \\
1965 & 7.2 \\
1966 & 7.3 \\
1967 & 6.1 \\
1968 & 7.3 \\
1969 & 5.0 \\
1970 & 7.2 \\
1971 & 6.8 \\
1972 & 5.3 \\
1973 & 6.3 \\
1975 & 5.2 \\
1976 &
\end{tabular}


Table 2 Year of diagnosis distribution of cancer diagnosed 1958-94 among offspring of pesticide applicators born 1958-94

\begin{tabular}{lc}
\hline Year of diagnosis & $\%$ \\
\hline $1965-69$ & 5.9 \\
$1970-74$ & 7.8 \\
$1975-79$ & 23.5 \\
$1980-84$ & 29.4 \\
$1985-89$ & 11.8 \\
$1990-94$ & 21.6 \\
\hline
\end{tabular}

\section{Kidney cancer}

An SIR of 0.27 (95\% CI 0.00 to 1.52 ) was found, based on one observed versus 3.7 expected cases.

\section{Soft tissue sarcoma}

Only one case was found versus 2.7 expected (SIR 0.38, 95\% CI 0.00 to 2.09).

\section{Cancer sites not included in the a priori hypotheses}

Noteworthy are two non-significant results; an increased SIR for endocrine glands of 1.62 (95\% CI 0.33 to 4.73$)$ and a decreased SIR for bone tumours of 0.54 (95\% CI 0.06 to 1.93 ).

\section{DISCUSSION}

Offspring of male pesticide applicators, who have used the most acutely toxic pesticides in agriculture, were in this study found to have a statistically significant decreased overall risk of cancer compared with the whole population. None of the a priori hypotheses could be confirmed. For leukaemia a significantly decreased risk was found.

An explanation of the decreased cancer risk could be that the offspring were brought up on farms and have had a healthier environment with regard to air pollution, exhausts, smoking, diet, drinking water, less stress, more physical activity, etc. There could, however, be a number of potentially hazardous agents on a farm, such as pesticides, solvents, motor vehicle fuels, lubricants, dusts, manure gases, infectious agents, mould, antibiotics, fungi, etc., some of which are known or suspected carcinogens. The fact that a blood relationship exists does not guarantee that a child has shared the environment with the father. However, farmers have the lowest rate of divorces in Sweden; for example, in 1960 the rate was $0.5 \%$ among farmers compared to $2.5 \%$ in the general population (personal communication with Gunilla Ringbäck, The National Board of Health and Welfare). Parental cancer has been shown to modify the risk of cancer in the offspring. ${ }^{34}$ Decreased risks in both pesticide applicators and their offspring suggest environmental and/or hereditary factors.

Children born 1958-60 and who have died before 1961 are not included in the offspring cohort. This will have the effect of underestimating the risk of cancer. However, a very conservative estimate is that 0.3 offspring would have been diagnosed with any type of cancer and died during these years.

Applicators smoke less than the general population and this has been used as an explanation for their lower incidence of cancer compared to the general population. Less passive smoking could contribute to the lower risk of cancer in their offspring.

Another question is whether the children are exposed enough to increase the cancer risk and whether it is feasible to use "license for pesticide application in agriculture" as a proxy for pesticide exposure, since neither the applicators nor their children have an increased cancer risk. There is no individual information of pesticide use in the pesticide applicator cohort. A random sample of 268 applicators was studied with reference to pesticide trade name, application days per year and years, application method, wearing protective clothing, tobacco habits, and occupational history during the 1950s, 1960s, and 1970s.$^{28}$ That study showed that few of the applicators worked full time applying pesticides. The most common occupations were in agriculture and/or forestry $(70 \%)$, and in horticulture $(10 \%)$. The remainder worked in a variety of occupations. The majority had used pesticides, some already during the 1950s. Wearing protective clothing has, despite the special education, been only slightly more frequent than among farmers in general, and as late as in the 1970 s about $50 \%$ never or seldom wore mask, glasses, or dress when applying pesticides.

In Sweden, the sales of phenoxy acid herbicides and other pesticides increased steeply from the introduction in the late 1940s until the middle of the 1970s. ${ }^{35}{ }^{36}$ Licensed pesticide applicators and farmers are the occupational groups most exposed to pesticides. Since 1965 it has been mandatory to have a licence for handling the most acutely toxic pesticides in Sweden. A cohort of 20245 pesticide applicators with licences issued between 1965 and 1976 was established

Table 3 Observed and expected number of cases 1958-94, by cancer site among offspring of pesticide applicators born 1958-94

\begin{tabular}{|c|c|c|c|c|}
\hline Site (ICD7) & Diagnosis & Obs & Exp & $\operatorname{SIR}(95 \% \mathrm{CI})$ \\
\hline 178 & Testis & 2 & 1.7 & $1.19(0.13$ to 4.28$)$ \\
\hline 180 & Kidney & 1 & 3.7 & $0.27(0.00$ to 1.52$)$ \\
\hline 190 & Malignant melanoma & 1 & 1.7 & $0.58(0.01$ to 3.24$)$ \\
\hline 192 & Eye & 2 & 2.6 & $0.76(0.09$ to 2.75$)$ \\
\hline 193 & Nervous system & 20 & 19.8 & $1.01(0.62$ to 1.56$)$ \\
\hline 193.0 & Brain (incl. meninges) & $17^{*}$ & 16.4 & $1.03(0.60$ to 1.65$)$ \\
\hline 194 & Thyroid gland & 1 & 1.3 & $0.78(0.01$ to 4.34$)$ \\
\hline 195 & Endocrine glands & 3 & 1.8 & 1.62 (0.33 to 4.73$)$ \\
\hline 196 & Bone & 2 & 3.7 & $0.54(0.06$ to 1.93$)$ \\
\hline 197 & Connective tissue, muscle & 1 & 2.7 & 0.38 (0.00 to 2.09$)$ \\
\hline 200 & Non-Hodgkin's lymphoma & 3 & 4.8 & $0.63(0.13$ to 1.83$)$ \\
\hline 201 & Hodgkin's disease & 5 & 3.7 & $1.36(0.44$ to 3.17$)$ \\
\hline \multirow[t]{2}{*}{204} & Leukaemia & 8 & 18.4 & $0.43(0.19$ to 0.86$)$ \\
\hline & Other & $2 \dagger$ & 7.0 & \\
\hline All & & 51 & 73.0 & 0.70 (0.52 to 0.92$)$ \\
\hline
\end{tabular}


earlier. Cancer risks in the cohort have been studied and reported in several papers. ${ }^{26-28} 3738$ Around $70 \%$ of the pesticide applicators were occupied in agriculture and the majority had used pesticides, some as early as in the 1950s.

There are some advantageous features specific for this study. The large cohort of pesticide applicators is unique and consists of the occupational group most exposed to pesticides in Sweden. Another advantage is that the Swedish Cancer Registry is population based, with high quality and coverage. $^{1} 3940$

Another advantage of this cohort study is that it is free from recall bias. Many studies of childhood cancer and pesticide use suffer from methodological limitations. Most of the previous epidemiological investigations have been casecontrol studies with few exposed cases and the possibility of recall bias.

A disadvantage of the study is that individual confounding factors and detailed pesticide exposure are not available, either for the pesticide applicators or their offspring.

"License for pesticide application in agriculture" was used as surrogate for pesticide exposure. However, the cancer risks associated with pesticide exposure in the general population would not be higher than among pesticide applicators and their offspring.

To further investigate a possible relation between paternal exposure to pesticide and cancer risk in their offspring, we plan to extend the cohort by adding pesticide applicators licensed in year 1977 and onwards by using information from The Swedish Board of Agriculture.

\section{ACKNOWLEDGEMENTS}

We thank the staff at The Centre for Epidemiology, The National Board of Health and Welfare for valuable help with the matching procedures and for fruitful discussions.

\section{Authors' affiliations}

Y Rodvall, Stockholm County Council and Department of Oncology-

Pathology, Karolinska Institutet, Stockholm, Sweden

J Dich, Department of Oncology-Pathology, Karolinska Institutet,

Stockholm, Sweden

K Wiklund, Department of Oncology-Pathology, Karolinska Institutet, Stockholm, Sweden

Financial support: Swedish Council for Social Research

\section{REFERENCES}

1 Centre for Epidemiology. Cancer incidence in Sweden 2000. Stockholm, Sweden: The National Board of Health and Welfare, 2002:5.

2 Kuijten RR, Bunin GR. Risk factors for childhood brain tumors. Cancer Epidemiol Biomarkers Prev 1993;2:277-88.

3 Ross JA, Davies SM, Potter JD, et al. Epidemiology of childhood leukemia, with a focus on infants. Epidemiol Rev 1994;16:243-72.

4 Zahm SH, Devesa SS. Childhood cancer: overview of incidence trends and environmental carcinogens. Environ Health Perspect 1995; 103(suppl 6): 177-84.

5 McBride ML. Childhood cancer and environmental contaminants. Can J Public Health 1998;89(suppl 1):53-62.

6 Savitz DA, Chen J. Parental occupation and childhood cancer: review of epidemiologic studies. Environ Health Perspect 1990;88:325-37.

7 Gold EB, Sever LE. Childhood cancers associated with parental occupational exposures. Occup Med 1994;9:495-539.

8 Feychting M, Plato N, Nise G, et al. Paternal occupational exposures and childhood cancer. Environ Health Perspect 2001;109:193-6.
9 Kristensen $\mathbf{P}$, Andersen A, Irgens LM, et al. Cancer in offspring of parents engaged in agricultural activities in Norway: incidence and risk factors in the farm environment. Int J Cancer 1996;65:39-50.

10 Zahm SH, Ward MH, Blair A. Pesticides and cancer. Occup Med 1997; 12:269-89.

11 Meinert R, Kaatsch P, Kaletsch U, et al. Childhood leukaemia and exposure to pesticides: results of a case-control study in northern Germany. Eur J Cancer 1996;32A: 1943-8.

12 Fear NT, Roman E, Reeves G, et al. Childhood cancer and paternal employment in agriculture: the role of pesticides. Br J Cancer 1998;77:825-9.

13 Zahm SH, Ward MH. Pesticides and childhood cancer. Environ Health Perspect 1998;106(suppl 3):893-908.

14 Meinert R, Schüz J, Kaletsch U, et al. Leukemia and non-Hodgkin's lymphoma in childhood and exposure to pesticides: results of a register-based casecontrol study in Germany. Am J Epidemiol 2000;151:639-46.

15 Cordier S, Mandereau L, Preston-Martin S, et al. Parental occupations and childhood brain tumors: results of an international case-control study. Cancer Causes Control 2001;12:865-74.

16 Daniels JL, Olshan AF, Savitz DA. Pesticides and childhood cancers. Environ Health Perspect 1997; 105:1068-77.

17 Lowengart RA, Peters JM, Cicioni C, et al. Childhood leukemia and parents' occupational and home exposures. J Natl Cancer Inst 1987;79:39-46.

18 Infante-Rivard C, Labuda D, Krajinovic M, et al. Risk of childhood leukemia associated with exposure to pesticides and with gene polymorphisms. Epidemiology 1999;10:481-7

19 Leiss JK, Savitz DA. Home pesticide use and childhood cancer: a case-control study. Am J Public Health 1995:85:249-52.

20 Pogoda JM, Preston-Martin S. Household pesticides and risk of pediatric brain tumors. Environ Health Perspect 1997; 105:1214-20.

21 Buckley JD, Medadows AT, Kadin ME, et al. Pesticide exposures in children with non-Hodgkin lymphoma. Cancer 2000;89:2315-21.

22 Moline JM, Golden AL, Bar-Chama N, et al. Exposure to hazardous substances and male reproductive health: a research framework. Environ Health Perspect 2000; 108:803-13.

23 Feldmann RJ, Maibach HI. Percutaneous penetration of some pesticides and herbicides in man. Toxcol Appl Pharmacol 1974;28:126-32.

24 Dich J. Cancer risks in Swedish applicators in agriculture, forestry and gardening. A toxicological and epidemiological approach. PhD dissertation, ISBN 91-628-3198-6. Stockholm, Sweden: Karolinska Institutet, 1998.

25 Bearer CF. How are children different from adults? Environ Health Perspect 1995; 103(suppl 6):7-12.

26 Wiklund K, Dich J. Cancer risks among male farmers in Sweden. Eur J Cancer Prev 1995;4:81-90.

27 Wiklund K, Dich J, Holm L-E, et al. Risk of cancer in pesticide applicators in Swedish agriculture. Br J Ind Med 1989;46:809-14.

28 Dich J, Wiklund K, Holm L-E. Testicular cancer in pesticide applicators in Swedish agriculture (letter). Scand J Work Environ Health 1996;22:66.

29 Hemminki K, Saloniemi I, Salonen T, et al. Childhood cancer and parental occupation in Finland. J Epidemiol Community Health 1981;35:11-15.

30 Olsen JH, De Nully Brown P, Schulgen G, et al. Parental employment at time of conception and risk of cancer in offspring. Eur J Cancer 1991;27:958-65.

31 Mutanen P, Hemminki K. Childhood cancer and parental occupation in the Swedish family-cancer database. J Occup Environ Med 2001;43:952-8.

32 Schüz J, Kaletsch U, Kaatsch P, et al. Risk factors for pediatric tumors of the central nervous system: results from a German population-based case-control study. Med Pediatr Oncol 2001;36:274-82.

33 Breslow NE, Day NE. Statistical methods in cancer research. Volume II-The design and analysis of cohort studies, IARC Scientific Publications No. 32. Lyon: International Agency for Research on Cancer, 1987.

34 Hemminki K, Vaittinen P, Kyyrönen P. Modification of cancer risk in offspring by parental cancer (Sweden). Cancer Causes Control 1999;10:125-9.

35 Dich J, Wiklund K. The use of phenoxy acid herbicides in Sweden. Chemosphere 1989;18:391-4.

36 National Central Bureau of Statistics. The natural environment in figures. Stockholm, Sweden: Statistics Sweden, 1990 (in Swedish, figures and tables in English).

37 Wiklund K, Dich J, Holm L-E. Testicular cancer among agricultural workers and licensed pesticide applicators in Sweden (letter). Scand J Work Environ Health 1986:12:630-1.

38 Wiklund K, Dich J, Holm L-E. Soft tissue sarcoma risk in Swedish licensed pesticide applicators. J Occup Med 1988;10:801-4.

39 Mattsson B, Wallgren A. Completeness of the Swedish Cancer Register. Nonnotified cancer cases recorded on death certificates in 1978. Acta Radiol Oncol 1984;23:305-13.

40 Mattsson B, Rutqvist L-E, Wallgren A. Comparison between diagnoses in the Stockholm Regional Cancer Register and certified underlying causes of death. Acta Radiol Oncol 1985;3:219-26. 